\title{
Our Experience of Laparoscopic Surgery in Children during the Learning Curve
}

Wani SA*, Mufti GN, Bhat NA, Baba AA, Khursheed S and Andrabi FH

Department of Paediatric Surgery, SKIMS, Soura, Srinagar, Jammu and Kashmir, India

\begin{abstract}
Aim: To address our experience of laparoscopic surgery in children during the learning curve.

Material and methods: This was a prospective analysis of patients who underwent various types of laparoscopic surgeries from January 2014 to August 2015. The different types of surgeries, operative time, conversion rate and complications were analyzed during this learning period.

Results: A total of 200 patients were operated and different types of lap procedures were performed, both basic and advanced. The majority of the laparosopic surgeries were cholecystectomy $82(41 \%)$, orchidopexy $31(15.5 \%)$, orchidectomy $6(3 \%)$, hydatid cyst liver $18(9 \%)$, appendectomy $14(7 \%)$, varicocelectomy $4(2 \%)$, pyloromyotomy 3 $(1.5 \%)$, ovarian tumour $7(3.5 \%)$, lap assisted pullthrough $4(2 \%)$, rectopey $3(1.5 \%)$ Meckles diverticulectomy $6(3 \%)$, spleenectomy $2(1 \%)$, mesenteric cyst $4(2 \%)$, diagnostic laparoscopy $9(4.5 \%)$, omental cyst $1(0.5 \%)$, duplication cyst $2(1 \%)$, nephrectomy $1(0.5 \%)$, leveling biopsy $2(1 \%)$, deroofing of left renal cyst $1(0.5 \%)$. During the early period of learning curve, operative time, conversion rate and complications were more which decrease with experience and learning skills. Conversions were for complicated appendicitis, hydatid cyst liver, spleenectomy and pyloromyotomy.

Conclusion: Laparoscopic surgery in children has lot of advantages, is very promising and techniquelly demanding. Complications do occur during the learning curve. The more operative time and more conversion rate during the learning curve should not be regarded as complication. Postdoctoral residents of pediatric surgery should be trained so that pediatric lap becomes widely available with good results.
\end{abstract}

Keywords: Laparoscopy; Pediatric; Learning curve

\section{Introduction}

Laparoscopic surgery in children is not new. The interest in laparoscopic surgery in children remained confined to a few enthusiasts initially and rest of the pediatric surgical community adopted a wait and see attitude [1-3]. However with increasing experience in pediatric laparoscopic procedures and advances in instrumentation, laparoscopy has become accepted in the modern pediatric surgical armamentarium [4-6]. In USA about $82 \%$ of pediatric surgeons perform laparascopic surgery [7]. At present most of the pediatric surgeon perform some form of laparoscopic surgery.

The laparoscopic surgery in children is increasing worldwide and the need for laparoscopic training has become essential in every teaching hospital. In this modern era it is very essential that every pediatric surgeon must have adequate training in laparoscopy. However, the learning curve in pediatric laparoscopy is long due to more complications and conversion rate during the learning curve. With the improvement in skill, the conversion rate and complications decrease with time during the learning curve. We present our experience of laparoscopic surgeries of 200 patients during the learning curve and discuss how the conversion, complications and operative time decrease with the time during the learning curve.

\section{Methods}

Patients up to the age of 16 years were operated laparoscopically by single surgeon having six months training in laparoscopy. Different surgical procedures were performed from January 2014 to August 2015. Pneumoperitonium was created by open method in all patients using carbon dioxide. The intra-abdominal pressure was maintained at $8 \mathrm{mmHg}$ in infants and $10-12 \mathrm{mmHg}$ in older children. The various types of surgeries, operative time, conversions and complications during the learning curve were analyzed.

\section{Results}

Different laparoscopic procedures were performed on 200 patients. The basic procedures were 149 (74.5\%) and advanced procedures 51(25.5\%) (Figure 1). The basic laparoscopic surgeries were cholecystectomy [82 (41\%)], orchidopexy [31 (15.5\%)], orchidectomy

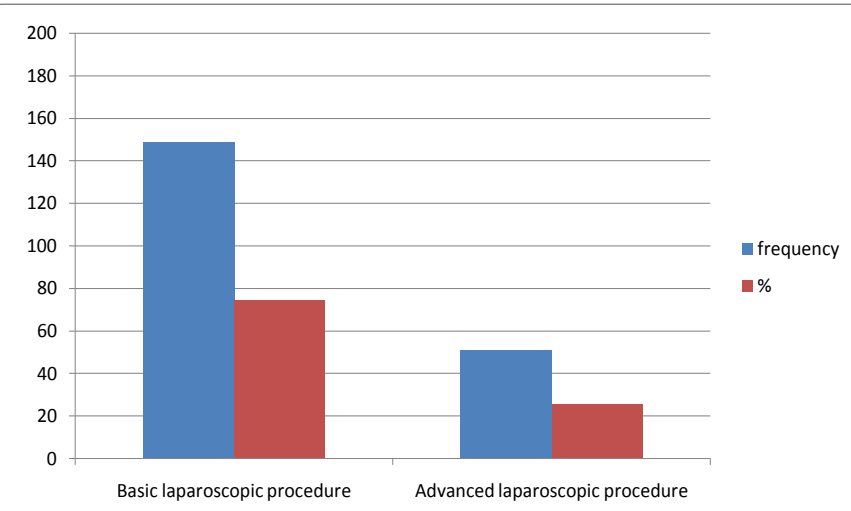

Figure 1: Basic and advanced laparoscopic surgeries.

*Corresponding author: Wani SA, SR, Department of Paediatric Surgery, SKIMS, Soura, Srinagar, Jammu and Kashmir, India, Tel: 9596310531; E-mail: ahmadsajadwani@gmail.com

Received December 18, 2015; Accepted February 10, 2016; Published February 20, 2016

Citation: Wani SA, Mufti GN, Bhat NA, Baba AA, Khursheed S, et al. (2016) Our Experience of Laparoscopic Surgery in Children during the Learning Curve. Med Rep Case Stud 1: 102. doi: 10.4172/2572-5130.1000102

Copyright: (C) 2016 Wani SA, et al. This is an open-access article distributed under the terms of the Creative Commons Attribution License, which permits unrestricted use, distribution, and reproduction in any medium, provided the original author and source are credited. 
[6 (3\%)], diagnostic laparoscopy [9 (4.5\%)], varicocelectomy [4 (2\%)], appendectomy [14 (7\%)], leveling biopsy 2 (1\%), deroofing of left renal cyst $1(0.5 \%)$. The advanced procedures were hydatid cyst liver [18 (9\%)], pyloromyotomy [3 $(1.5 \%)]$, ovarian tumour [7 $(3.5 \%)]$, lap assisted pullthrough [4 (2\%)], rectopey [3 (1.5\%)], Meckles diverticulectomy [6 (3\%)], spleenectomy [2(1\%)], mesenteric cyst [4 $(2 \%)]$, omental cyst $1(0.5 \%)$, duplication cyst $2(1 \%)$, nephrectomy 1 (0.5\%).

Our operative time was initially more which subsequently decrease with time and experience. The longest operative time was one hour and thirty min for hydatid cyst liver which subsequently decreased to 25 to 30 minutes.

In our patients conversion rate and complications were more during the early months of learning curve. Conversions were for complicated appendicitis, hydatid cyst liver, spleenectomy and pyloromyotomy. The complications were diathermy induced lateral $\mathrm{CBD}$ injury in one patient, which reported six days after discharge and was managed by T-tube (Figure 2). Cetrimide induced peritonitis occurred in two patients, one patient was explored and another patient was management conservatively. Fecolith induced peritonitis in one patient which has probably dropped during removal of specimen. Delayed haemoperitonium in one lap orchidectomy patient. This patient reported two days after discharge and was managed conservatively.

\section{Discussion}

The field of laparoscopy surgery in children is wide, ranging from basic to advanced procedures. The main advantages of laparoscopy surgeries are less pain, scar less, shorter hospital stay, early return to normal activities, early return to school, early resumption to work by parents, operations in deep cavities of small children etc. However laparoscopy is not without complications and there is a learning curve and skills have to be maintained and improved.

The data on learning curve in laparoscopy in children is lacking. For lap cholecystectomy, the learning curve ranges from 10 to 75 procedures [7]. For fundoplication it is about 25 procedures [8]. For spleenectomy, the learning curve is minimum of 20 cases [9]. For pyloromyotomy good results are achieved after 35 procedures [10]. More complication rate and more severe complications in the early part of learning curve is very frustrating and uncomfortable time for the surgeon, especially when excellent results are achieved by open surgery. The is one of the important reason that many pediatric surgeons are early in their learning curve due to fear of complications, more conversion rate and poor results. A recent survey has shown that many pediatric surgeons are in their learning curve [7].

Most of the complications of pediatric laparoscopic surgery are technique related. The dreaded complications are hemorrhage, visceral

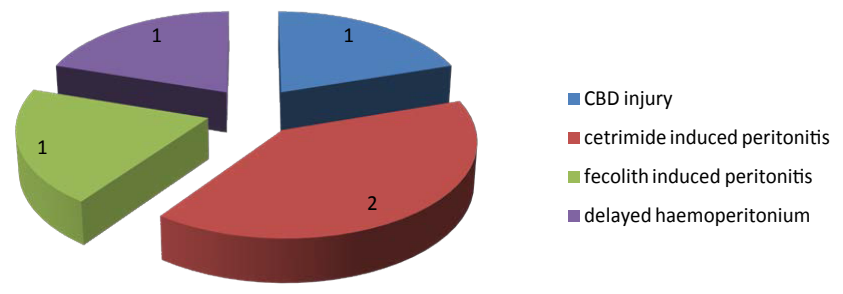

Figure 2: Complications. or vessel injury during trocar insertion, diathermy injury to gut, or CBD. In large centers, a complication rate of $1-2 \%$ has been reported in laparoscopic surgery in children [11]. The more operative time or conversion to open should not be regarded as a complication but more operative time or conversion to prevent the complication is very important and safe for the surgeon and to gain the confidence during the learning curve. In our patients, the operative time, conversion rate and complications were more during the early period of learning curve, which decrease with time, experience and learning skills. Now we are doing more advanced procedures with good results. The complications which occurred in our patients can be prevented by learning the lesson from such complications. The use of cetrimide in hydatid cyst should be used cautiously, be careful and vigilant during the removal of specimen and its contents, careful application of clips on testicular vessel during the lap orchidectomy or Stephen Fowhler orchidopexy, use open method for the creation of pneumoperitonium. New trainee's particularly postdoctoral trainees should be trained, so that in future laparoscopic surgery in children is widely and easily available with excellent results.

\section{Conclusion}

Laparoscopic surgery in children has lot of advantages and is very promising, but complications do occur during the learning curve. The more operative time or conversion to open should not be regarded as a complication; rather it is safe for the surgeon and to gain the confidence during the learning curve. Operative time, conversion rate and complications decrease with time, experience and learning skills. Postdoctoral residents of pediatric surgery should be well trained in pediatric laparoscopy, so that laparoscopic surgery in children becomes widely available with good results.

\section{References}

1. Sackier JM (1991) Laparoscopy in pediatric surgery. J Pediatr Surg 26 1145-1147.

2. Miller SS (1992) Laparoscopic operations in paediatric surgery. Br J Surg 79 986-987.

3. Najmaldin A (1995) Minimal access surgery in paediatrics. Arch Dis Child 72: 107-109.

4. Lobe T (1998) Laparoscopic surgery in children. Curr Probl Surg 35: 861-948.

5. Rothenberg SS, Chang JHT, Bealer JF (1998) Experience with minimally invasive surgery in infants. Am J Surg 176: 654-658.

6. Chung DH, Georgeson KE (1998) Fundoplication and gastrostomy. Semin Pediatr Surg 7: 213-219.

7. Firilas AM, Jackson RJ, Smith SD (1988) Minimally invasive surgery: the pediatric surgery experience. J Am Coll Surg 186: 542-544.

8. Meehan JJ, Georgeson KE (1997) The learning curve associated with laparoscopic antireflux surgery in infants and children. J Pediatr Surg 32: 426-429.

9. Peters MB Jr, Camacho D, Ojeda H, Reichenbach DJ, Knauer EM, et al (2004) Defining the learning curve for laparoscopic splenectomy for immune thrombocytopenia purpura. Am J Surg 188: 522-525.

10. Oomen MW, Hoekstra LT, Bakx R, Heij HA (2010) Learning curve for pediatric laparoscopy: how many operations are enough? The Amsterdam experience with laparoscopic pyloromyotomy. Surg Endosc 24: 1829-1833.

11. Chen MK, Schropp KP, Lobe TE (1996) Complications of minimal-access surgery in children. J Pediatr Surg 31: 1161-1165. 